\title{
Effects of Simultaneous Exposure to Formaldehyde Vapor and Noise on Mouse Testicular Tissue and Sperm Parameters
}

\author{
Shahram Vosoughi ${ }^{1}$, Ali Khavanin ${ }^{1^{*}}$, Mojdeh Salehnia ${ }^{2}$, Hassan Asilian Mahabadi ${ }^{1}$, Ardalan \\ Soleimanian ${ }^{1}$ \\ ${ }^{1}$ Department of Occupational and Environmental Health, School of Medical Sciences, Tarbiat Modares University, Tehran, IR Iran \\ 2 Department of Anatomical Sciences, School of Medical Sciences, Tarbiat Modares University, Tehran, IR Iran
}

\begin{tabular}{l}
\hline A R T I C L E I N F O \\
\hline Article type: \\
Research Article \\
\hline Article history: \\
Received: 28 Aug 2012 \\
Revised: 01 Sep 2012 \\
Accepted: 07 Sep 2012
\end{tabular}

\begin{abstract}
A B S T R A C T
Background: Workers are often simultaneously exposed to formaldehyde and noise in workplaces, and noise can reinforce the harmful effects of some chemical pollutants. objectives: This study aimed to investigate the effects of simultaneous formaldehyde and noise exposure on reproductive parameters in male mice.

Materials and Methods: Forty eight National Medical Research Institute adult male mice were randomly assigned to control and experimental groups which were exposed to formaldehyde (10 ppm) (F), noise (100 dB) (N), and simultaneous formaldehyde with noise (NF), respectively for 10 days (8 hours a day). Animals were killed 24 hours following exposure (short-term effects) and the remainder was killed 35 days after the end of exposure (long-term effects). Sperm was analyzed by a computer aided sperm analysis system and histological changes in the testis were determined. Plasma concentrations of testosterone, LH, FSH were measured.

Results: The results of the short-term analysis showed that serum testosterone in all exposure groups decreased significantly compared to the controls $(P<0.001)$. In the longterm analysis, the percentages of progressive motile sperm groups $\mathrm{N}, \mathrm{F}$, and NF were 33.73 $\pm 3.4,26.65 \pm 1.61$, and $14.78 \pm 4.65$, respectively, which indicated a significant decrease $(P<$ $0.05)$ compared to the control group $(44.47 \pm 2.88)$. The progressive motile sperm in the simultaneous exposure group was less than the $\mathrm{N}$ and $\mathrm{F}$ groups $(P<0.001)$. Histological study of testes specimens in the experimental groups (F and NF) revealed displacement of germinal cells and degeneration of Leydig cells and seminiferous tubules.

Conclusion: Exposure to formaldehyde vapor can destroy testicular structure and decrease percentages of sperm count and progressive motility. The present study indicated that a reduction in the percentage of progressive motile sperm may be potentiated by noise (700-5700 HZ) in the simultaneous exposure to formaldehyde and noise group. Thus, it can be anticipated that simultaneous exposure to formaldehyde and noise in workplaces can increase the possibility of damage to testicular structures and reproductive functions in humans, if the same effects transpire.
\end{abstract}

Keywords:

Formaldehyde

Noise

Gonadal Steroid Hormones

Mice

- Implication for health policy/practice/research/medical education:

This article has focused on investigating the effects of simultaneous formaldehyde and noise exposure on reproductive parameters in male mice.

\footnotetext{
* Corresponding author: Ali Khavanin, Jalale-Ale-Ahmad Highway, Tarbiat Modares University, Faculty of Medical Sciences, Department of Occupational and Environmental Health, P.O. Box 14115-175, Tehran, IR Iran. Tel:+98-2182883825, Fax: +98-2182883825, E-mail: khavanin@modares.ac.ir
} 
Please cite this paper as:

Vosoughi S, Khavanin A, Salehnia M, Asilian Mahabadi H, Soleimanian A. Effects of Simultaneous Exposure to Formaldehyde Vapour and Noise on Mouse Testicular Tissue and Sperm Parameters. Health Scope. 2012; 1 (3): 110-7.

\section{Background}

Formaldehyde (H2CO) is a colorless, flammable, chemical precursor, which is widely used in various industries. The World Health Organization (WHO) has defined 36 industries in which workers are exposed to formaldehyde (1). Formaldehyde is considered to be an economically important substance. The production of this material has increased from 23.21 million tons in 2000 , to 36 million tons in 2007 , which is a $70 \%$ increase during seven years (2). Industries or occupations with significant formaldehyde exposure include; medical specialties (coroners, hospital housekeeping staff, and laboratory workers), embalmers, industrial workers (formaldehyde synthesis, molding compounds, decorative laminates, plastic moldings and photographic films), textile and wood workers (plywood, particle board and furniture) (2).

Impairments resulting from high noise levels have been reported as one of the ten most hazardous occupational factors. Based on research and statistics in the United States, 7.4-10.2 million workers are exposed to noise stress (3). In Europe, more than $26 \%$ of the population are exposed to environmental noise levels higher than $65 \mathrm{~dB}$ (4). The harmful effects of formaldehyde in the air have been well documented for the respiratory system, these include; nasal squamous cell carcinoma and mutagenicity (5). However, its effects on other systems and organs are still being studied. Chowdhury et al. (6) noted an inhibition of steroidogenesis, disruption of Leydig cells and spermatogenesis arrest, that resulted from intraperitoneal injections of formaldehyde at dosages of 5, 10 and $15 \mathrm{mg} / \mathrm{kg}$ in rats. The negative impact of formaldehyde exposure and sperm parameters has been investigated in several studies $(7,8)$. Zhou et al. reported the effects of formaldehyde on reproductive functions in mice that were exposed to formaldehyde $\left(10 \mathrm{mg} / \mathrm{m}^{3}\right)$ for 2 weeks (12 hours a day) (9). The results revealed atrophy of the seminiferous tubules, decreased sperm count and sperm progressive motility in the epididymis. It was shown that exposure to formaldehyde increased the secretion of corticotrophin releasing hormone ( $\mathrm{CRH}$ ) from the hypothalamus and caused corticosteroid adrenal release which decreased testosterone hormone by affecting the hypothalamus-pituitary-testis (HPT) axis (10).

Noise is one of the hazardous factors in the workplace that activates nerve-hormone tracts and consequently increases catecholamine, glucocorticoids and cortisol plasma (11). Decreases in testosterone hormone levels were found in adult male rats exposed to noise $(100 \mathrm{~dB}, 1000$ $\mathrm{HZ}$ ) for a period of 60 days (3 hours a day) (12). Further- more, Fathollahi, et al. (13) exposed rats to noise (90-130 $\mathrm{dB}$ ) for 50 days (12 hours a day). They reported a significant decrease in testosterone, FSH, and LH levels, as well as a negative impact on fertility in rats.

\section{Objectives}

So far, several studies have investigated the effects of formaldehyde and noise on the reproductive system in animal models (14). However, there is inadequate information concerning their toxic effects on reproductive system functioning. Thus, the present research attempts to examine the effects of simultaneous formaldehyde and noise exposure on the means of seminiferous tubular diameters (STD), gonadotropic hormonal changes and sperm parameters in mice.

\section{Materials and Methods}

\subsection{Animals and Experimental Design}

Forty eight NMRI adult male mice (25-35 gr), aged 7-8 weeks were purchased from the Pasteur Institute, Tehran. The mice were transferred to the animal house in the Tarbiat Modares University one week before exposure in order to adapt to the environment. In the animal house, they were kept at a temperature of $23 \pm 2^{\circ \mathrm{C}}$, humidity of $40-50 \%$, and a $12 \mathrm{~h}$ light, $12 \mathrm{~h}$ dark photoperiod. All mice were given a standard diet and water ad libitum throughout the study period. The ethical considerations of working with animals were followed according to the guidelines of Tarbiat Modares University. The mice were randomly allocated to three experimental groups and a control group, according to the study design with approximately equal mean body weights.

Group C: Control group which were in an experimental condition, but were not exposed to formaldehyde or noise $(n=12)$.

Group N: Animals that were exposed to noise $(n=12)$.

Group F: Animals that were exposed to formaldehyde $(10 \mathrm{ppm})(\mathrm{n}=12)$.

Group NF: Animals that were exposed to formaldehyde $(10 \mathrm{ppm})$ and noise simultaneously $(\mathrm{n}=12)$.

The mice were placed in a vitreous plexiglass quadrangular chamber $(30 \times 25 \times 29 \mathrm{~cm})$ that contained two holes for the in- and out-flow of air. Two loudspeakers were installed on the roof of the chamber at specific points as sources of sound. Air circulation in the chamber was at a fixed flow rate (12 times per hour) maintained by air pumps. Formaldehyde vapor was generated by thermal depolymerisation of para-formaldehyde (Merck AG, Darmstadt, Germany) at $70-90^{\circ} \mathrm{C}$ according to a method 
described by Change et al. (15) and this was measured and monitored four times an hour, by a photo ionization detector (Photocheck + 5000, Ionscience Co., UK). Precision of the measurement was controlled according to the 3500 method recommended by the National Institute of Occupational Health and Safety (NIOSH) $(15,16)$.

Selection of the materials and dimensions of the chamber, to make a reverberant chamber with defined dimensional proportions, were based on Bolt's chart, and the mice were exposed to a spectrally homogeneous sound field (100 \pm 2 $\mathrm{dB}$ ) at each point inside the reverberant chamber with a mini speaker (Visaton K50-RC) $(17,18)$. The mice in groups $\mathrm{N}$ and NF were exposed to 700-5700 HZ noise (combination of three octave-band sound, 1000-2000-4000 HZ, $100 \pm 2$ $\mathrm{dB})$. Moreover, the mice in groups $\mathrm{F}$ and NF were exposed to formaldehyde (10 ppm) for 10 days ( 8 hours a day). The mice in the control group inhaled air during the exposure period and were exposed to background noise (less than 50 $\mathrm{dB}$ ) in the laboratory. Using the signal software, the noise waves with the abovementioned frequency combination were produced and performed on the computer by Cool Edit software (19). The sound was broadcast in the chamber by an amplifier and loudspeakers and monitored by an analyzer sound level meter (CEL-490, Casella Cel Co., UK) in terms of frequency and intensity during the exposure period. The microphone of the sound level meter was placed inside the chamber during the exposure and, in the case of any change, was regularly controlled and edited by the edit software. The intensity of the background sound in the animal house and laboratory was less than $50 \mathrm{db}$ for all of the groups. After the last day of the exposure period, at two specific times, one after the last day of exposure and the other 35 days after the exposure, the mice were sacrificed using cervical dislocation after blood was taken from the heart. Testes and epididymis were removed by creating a cut in the scrotum. The prepared serum was preserved at a temperature of $20^{\circ} \mathrm{C}$ until the time of testosterone measurement (n $=6$ in each group, in each period). Subsequently, the testes were separated from the epididymis and the epididymis was then put in the medium.

\subsection{Epididymal Sperm Preparation and Sperm Quality Evaluation}

For epididymal sperm preparation, mice were sacrificed by cervical dislocation either 24 hours or 35 days after the end of the exposure period. The cauda epididymides were dissected and placed in $1 \mathrm{ml}$ pre-warmed Ham's F-10 (nutrient mixture-Ham-X1, Gibco, UK) culture medium with $10 \%$ fetal bovine serum (Gibco, UK). Gentle agitation along with tearing of the tissue was applied to enable the spermatozoa to swim out into the medium in a Falcon culture dish (20). Semen samples were incubated at $37^{\circ} \mathrm{C}$ for 30 minutes before analysis of sperm parameters. Sperm count and motility were analyzed with a computer-assisted sperm analyzer (CASA) as described by Krause (20). The CASA system consisted of a phase contrast microscope (Eclipse E-200, Nikon Co., Japan) with a heat plate equipped with Sperm Class Analyzer® software (SCA, full research version 5.1, Microptic Co., Barcelona, Spain). Images were captured by a video camera (Basler Vision, A312FC at $50 \mathrm{fps}$, Tecnologie Co., Ahrensburg, Germany) at 100x magnification. For this purpose, $4 \mu \mathrm{l}$ sperm samples were placed in a standard count analysis chamber (Leja, Nieuw Vennep Co., Netherlands). The loaded chamber was placed on the warm plate of the microscope $\left(37^{\circ} \mathrm{C}\right)$ for 3 minutes before analysis. Then, the specimens were observed with a Nikon microscope 10 $\mathrm{x} / 0.25$ negative phase contrast field $\mathrm{Ph} 1 \mathrm{BM}$, with an intermediate magnification of 0.7 and a green filter. To assess the percentage of viable sperm, we performed eosin- $Y$ staining by mixing $10 \mu \mathrm{l}$ of the sperm sample with $10 \mu \mathrm{l}$ of dye ( $0.5 \% \mathrm{wt} / \mathrm{vol}$, Merck Chemical Co., Germany) on a microscope slide and covered with a coverslip. A total of 200 sperm cells were counted within a few minutes after the addition of the dye (21). Evaluation of live (unstained) and dead (red stained) spermatozoa was carried out using light microscope at 400x magnification.

\subsection{Histological Analysis and Morphometric Technique}

For the histological examination, testicular tissues were dissected and samples fixed in Bouin's fixative for 24 hours, then processed by a graded ethanol series and embedded in paraffin. The paraffin sections were cut in $5 \mu \mathrm{m}$ thick slices and stained with hematoxylin and eosin for light microscopic examination (22). Sections were viewed and photographed by a microscope (Magnum-3, Ceti, England) with an attached camera (Sony-DSC-H50). An estimate of seminiferous tubular diameters (STD) was performed by examining 20 fields in five histological sections from each testis (22), using digitalized microscopic images (10X) with software Image Tools 3.0 (http://compdent.uthscsa.edu/dig/itdesc.html).

\subsection{Hormone Assay}

Blood samples were collected from all subjects and serum specimens were separated by centrifugation at 3000 $\times \mathrm{g}$ for $15 \mathrm{~min}$ and they were collected and frozen at $-20^{\circ} \mathrm{C}$ until analysis. Serum levels of testosterone, LH, FSH were evaluated using a commercially available enzyme-linked immunoassay (23) kit (Monobind Inc., USA, Product code Testosterone: 3775-300, Product code LH: 675-300, Product code FSH: 475-300) according to the manufacturer's instructions.

\subsection{Statistical Analysis}

All statistical analyses were carried out using SPSS statistical software version 11.5 (SPSS, Inc., Chicago, IL). All data were expressed as mean \pm SD. Comparisons between the control and formaldehyde exposed groups were per- 
formed using one-way analysis of variance (ANOVA), followed by a Scheffe 's test. The level of statistical significance was set at $P<0.05$.

\section{Results}

\subsection{Sperm Parameters}

The results obtained from the short-term analysis of the physiological parameters of epididymis sperm (24 hours after exposure) did not show any significant differences in the N, F, and NF experimental groups in term of sperm count, sperm motility and percentage of sperm viability in comparison with the control group (Table 1). The results of the study in the long-term analysis indicated that the mean of sperm viability in the control group was $82.33 \pm 4.63$ and in the experimental groups; N, F, and NF, the means were $64.33 \pm 4.84,61.33 \pm 5.85$ and $47.33 \pm 1.97$, respectively. A comparison of the results in the exposure groups with the control group showed a significant decrease in sperm viability in all exposure groups. Furthermore, a comparison of the groups with each other revealed that the difference between experimental groups $\mathrm{N}$ and F in comparison with NF was statistically significant $(P<0.05)$. Moreover, the means of the epididymis sperm count in the experimental groups N, F, and NF were 3.16 $\pm 0.42,2.87 \pm 0.51$, and $2.22 \pm 0.51$, respectively compared to the control group $(5.08 \pm 0.65)$ which was statistically significant $(P<0.05)$. The results of a post-hoc Scheffé's test, however, showed no significant differences between the experimental groups (Table 1). The results of the longterm analysis of the sperm motility mean (35 days after exposure) indicated that percentages of epididymis progressive motile sperm in the experimental groups $\mathrm{N}, \mathrm{F}$, and NF were $33.73 \pm 3.48,26.65 \pm 1.61$, and $14.78 \pm 4.65$, respectively which showed a significant decrease $(P<0.05)$ compared to the control group $(44.47 \pm 2.88)$. However, no significant differences were observed in the percentage of progressive sperm between experimental groups $\mathrm{N}$ and $\mathrm{F}(P>0.05)$, although the study showed that there was a significant difference in the percentage of progressive sperm in groups $\mathrm{N}$ and $\mathrm{F}$ in comparison with the simultaneous exposure group NF $(P<0.01)$ (Table 1$)$.

\subsection{Testicular Histopathology}

Histological examination of the test showed numerous structural changes in the $\mathrm{F}$ and NF experimental groups (long-term analysis) in comparison with the control. The main pathological changes included; seminiferous tubule atrophy, increases in the spaces between germ cells, degeneration of Leydig cells, disintegration of seminiferous epithelial cells and degeneration of a number of seminiferous

Table 1. Differences in Mouse Sperm Parameters in Experimental Groups, 24 Hours (Short-Term Analysis) and 35 Days (Long-Term Analysis) After Exposure (mean \pm SD).

\begin{tabular}{|c|c|c|c|c|c|}
\hline & $\begin{array}{l}\text { Sperm Count, } 10^{6} / \\
\text { ml }\end{array}$ & $\begin{array}{l}\text { Progressive, Mo- } \\
\text { tility (\%) }\end{array}$ & $\begin{array}{l}\text { Non-Progressive, } \\
\text { Motility (\%) }\end{array}$ & Immotile, \% & Sperm Viability, \% \\
\hline \multicolumn{6}{|l|}{ Short-term analysis } \\
\hline \multirow[t]{2}{*}{ Control noise } & $4.77 \pm 0.56$ & $42.87 \pm 4.05$ & $37.62 \pm 7.09$ & $19.52 \pm 4.05$ & $82.17 \pm 3.49$ \\
\hline & $3.67 \pm 0.59$ & $39.82 \pm 5.77$ & $40.72 \pm 3.67$ & $19.45 \pm 5.26$ & $81.27 \pm 4.70$ \\
\hline Formaldehyde & $3.93 \pm 1.09$ & $39.72 \pm 5.72$ & $34.37 \pm 4.94$ & $26.08 \pm 6.12$ & $75.33 \pm 5.89$ \\
\hline Noise-formaldehyde & $2.97 \pm 1.18$ & $37.90 \pm 3.78$ & $33.80 \pm 6.07$ & $28.30 \pm 5.57$ & $73.12 \pm 5.74$ \\
\hline \multicolumn{6}{|l|}{ Long-term analysis } \\
\hline \multirow[t]{2}{*}{ Control noise } & $5.08 \pm 0.65$ & $44.47 \pm 2.88$ & $37.93 \pm 3.12$ & $17.58 \pm 5.34$ & $83.33 \pm 4.63$ \\
\hline & $3.17 \pm 0.42^{a, e}$ & $33.73 \pm 3.48^{a, d}$ & $27.17 \pm 5.74^{\mathrm{a}, \mathrm{d}}$ & $39.08 \pm 5.32^{\mathrm{a}, \mathrm{e}}$ & $64.33 \pm 4.84^{\mathrm{a}, \mathrm{d}}$ \\
\hline Formaldehyde & $2.87 \pm 0.51^{\mathrm{b}, \mathrm{e}}$ & $26.65 \pm 1.61^{\mathrm{b}, \mathrm{e}}$ & $33.08 \pm 5.61$ & $40.27 \pm 6.38^{\mathrm{b}, \mathrm{e}}$ & $61.33 \pm 5.85^{\mathrm{b}, \mathrm{e}}$ \\
\hline Noise-formaldehyde & $2.22 \pm 0.51^{c, e}$ & $14.78 \pm 4.65^{\mathrm{c}, \mathrm{e}}$ & $29.95 \pm 4.57$ & $55.12 \pm 2.21^{\mathrm{c}, \mathrm{e}}$ & $47.33 \pm 1.97^{c, d}$ \\
\hline
\end{tabular}

${ }^{\text {a }}$ Difference between experimental group $(\mathrm{N})$ and control group

${ }^{\mathrm{b}}$ Difference between experimental group (F) and control group

${ }^{\mathrm{c}}$ Difference between experimental group (NF) and control group

${ }^{d} P<0.05$

${ }^{\text {e }} P<0.001$

\begin{tabular}{lllll}
\hline Table 2. Comparison of seminiferous tubular diameter(STD) Means in Control and Exposure Groups (One-Way ANOVA and Scheffe-"s Tests). \\
\hline & $\begin{array}{l}\text { STD in Mice Sacrificed 24 Hours Af- } \\
\text { ter Exposure, Mean } \pm \text { SD }\end{array}$ & $\begin{array}{l}\text { P-Value, Versus } \\
\text { Control Group }\end{array}$ & $\begin{array}{l}\text { With } \\
\text { CTD in Mice Sacrificed 35 Dayss } \\
\text { After Exposure, Mean } \pm \text { SD }\end{array}$ & $\begin{array}{l}\text { P-Value, Versus With } \\
\text { Control Group }\end{array}$ \\
\hline C & $233.33 \pm 6.055$ & & $235.17 \pm 5.742$ & $<0.05$ \\
N & $224.83 \pm 5.382$ & 0.354 & $219.33 \pm 6.121$ & $<0.001$ \\
F & $218.83 \pm 5.913$ & $<0.05$ & $210.33 \pm 5.465$ & $<0.001$ \\
\hline NF & $216.33 \pm 5.680$ & $<0.05$ & $203.67 \pm 5.989$ & \\
\hline
\end{tabular}

Abbreviations: Group C, controls; Group N, exposed to noise (100 dB, 700-5700 Hz); Group F, exposed to formaldehyde (10 ppm); Group $\mathrm{NF}$, exposed to formaldehyde and noise. 
Table 3. Comparison of the Means of Serum Sexual Hormone Concentration in Control and Exposure Groups (One-Way ANOVA and Scheffe"'s Test).

\begin{tabular}{|c|c|c|c|c|}
\hline & $\begin{array}{l}\text { Hormone Concentration in } \\
\text { Serum } 24 \text { Hours After Exposure, } \\
\text { Mean } \pm \text { SD }\end{array}$ & $\begin{array}{l}\text { P-Value, (Versus } \\
\text { With Control Group) }\end{array}$ & $\begin{array}{l}\text { Hormone Concentration in } \\
\text { Serum } 35 \text { Days After Exposure, } \\
\text { Mean } \pm \text { SD }\end{array}$ & $\begin{array}{l}\text { P-Value, Versus With } \\
\text { Control Group }\end{array}$ \\
\hline & Testosterone & & Testosterone & \\
\hline C & $3.82 \pm 0.35$ & & $3.62 \pm 0.15$ & \\
\hline $\mathbf{N}$ & $2.73 \pm 0.24$ & $<0.001$ & $3.32 \pm 0.27$ & 0.337 \\
\hline $\mathbf{F}$ & $2.58 \pm 0.16$ & $<0.001$ & $3.24 \pm 0.23$ & 0.134 \\
\hline \multirow[t]{2}{*}{ NF } & $2.03 \pm 0.22$ & $<0.001$ & $3.16 \pm 0.13$ & $<0.05$ \\
\hline & Luteinizing hormone (LH) & & Luteinizing hormone (LH) & \\
\hline $\mathbf{C}$ & $4.23 \pm 0.22$ & & $4.26 \pm 0.14$ & \\
\hline $\mathbf{N}$ & $4.05 \pm 0.12$ & 0.795 & $4.18 \pm 0.24$ & 0.984 \\
\hline $\mathbf{F}$ & $3.59 \pm 0.28$ & $<0.05$ & $4.05 \pm 0.17$ & 0.584 \\
\hline \multirow[t]{2}{*}{ NF } & $2.85 \pm 0.15$ & $<0.001$ & $4.01 \pm 0.20$ & 0.346 \\
\hline & Follicle stimulation hormone(FSH) & & Follicle stimulation hormone(FSH) & \\
\hline C & $6.02 \pm 0.46$ & & $6.15 \pm 0.40$ & \\
\hline $\mathbf{N}$ & $5.98 \pm 0.29$ & 1.000 & $6.07 \pm 0.18$ & 0.999 \\
\hline $\mathbf{F}$ & $5.71 \pm 0.29$ & 0.603 & $5.88 \pm 0.40$ & 0.793 \\
\hline NF & $5.23 \pm 0.19$ & $<0.05$ & $5.78 \pm 0.36$ & 0.490 \\
\hline
\end{tabular}

Abbreviations: Group C, controls; Group N, exposed to noise (100 dB, 700-5700 Hz); Group F, exposed to formaldehyde (10 ppm); Group $\mathrm{NF}$, exposed to formaldehyde and noise.

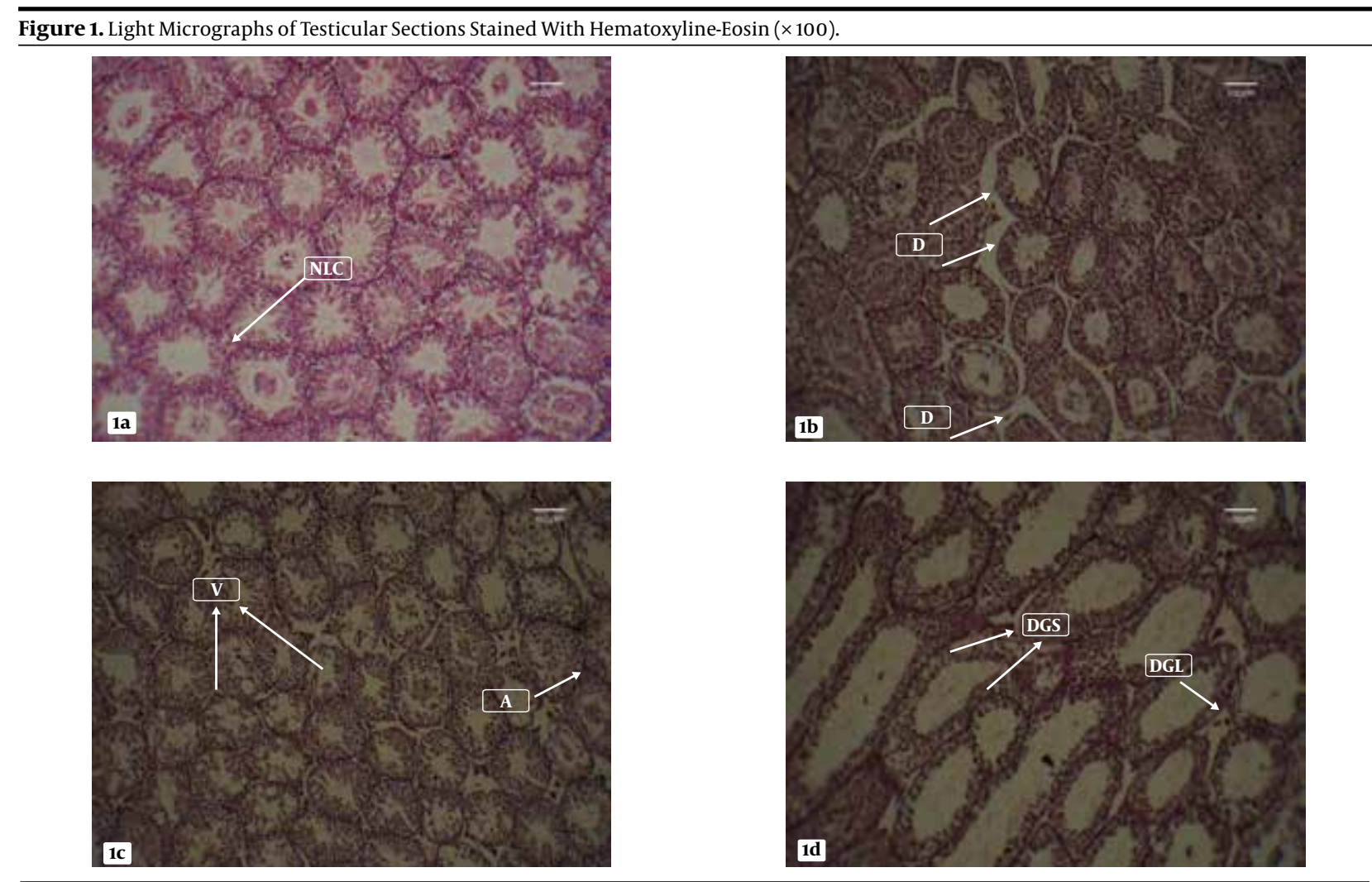

1a: Normal histological structure in seminiferous tubules was seen in the control group.

1b: Exposure to N-100 dB, 700-5700 Hz-(long-term analysis), showing normal spermatogenic cells and seminiferous tubules, and an apparant increase in inter-tubular specimens.

1c: Exposure to formaldehyde vapor at $10 \mathrm{ppm}$ (long-term analysis) showing atrophy and disruption of germ cells in seminiferous tubules and vacuolization of seminiferous epithelium.

1d: Exposure to NF (long-term analysis) showing degeneration in Leydig cells and seminiferous tubules.

Abbreviations: A, atrophy; D, disruption; DGL, degeneration in Leydig cells; DGS, degeneration in seminiferous tubules; NLC, normal Leydig cells; and V, vacuolization. 
tubules. No histological changes were seen in the control specimens (Figure $1 A-D$ ). The morphometric findings indicated that the mean of seminiferous tubular diameters (STD) decreased significantly in both the short $(P<0.05)$ and long-term $(P<0.001)$ analysis in the experimental groups when compared with the control group (Table 2).

\subsection{Gonadotropic Hormonal}

The short-term and long-term analysis of mean values for serum levels of testosterone, LH, FSH from all subjects in both the control and exposure groups are shown in Table 3. Our data in the short-term analysis indicated that testosterone declined significantly in all experimental groups, N, F, and NF $(P<0.001)$, similarly, serum levels of $\mathrm{LH}$, were significantly reduced in the exposure groups $\mathrm{F}$ and NF, compared with the control group $(P<0.05, \mathrm{P}<$ 0.001). Also, a comparison of the serum levels of FSH in the exposure and control groups indicated that there was a statistically significant decrease only in the simultaneous exposure group NF $(P<0.05)$. In the long-term analysis, mean values for testosterone, $\mathrm{LH}$, and FSH hormone levels in the experimental groups increased in comparison to the same groups in the short-term analysis. The means of these hormones with exposure to noise, and exposure to formaldehyde groups, were not statistically significant compared to the control group $(P>0.05)$. Moreover, while the level of testosterone hormone in the simultaneous exposure group in the short-term analysis had increased, there was a significant difference observed in comparison with the control group $(P<0.05)$.

\section{Discussion}

The present study has shown that there is an inhibitory effect of formaldehyde vapor on mouse sperm resulting in decreased sperm motility after formaldehyde vapor exposure is potentiated by simultaneous noise exposure. The effects of formaldehyde on male fertility potential in some mammals has been investigated previously, but to our knowledge there are few reports on the effects of simultaneous formaldehyde and noise exposure on sperm motility in short (one day) and long duration (35 days) exposure times. The results of the long-term analysis revealed that formaldehyde vapor alone, or in combination with noise exposure, decreased progressive motile sperm in mice. In fact, our results involve novel information about the effect that simultaneous formaldehyde and noise exposure has on sperm progressive motility, in regard to the detrimental reinforced effects of noise on sperm motility in mice $(24,25)$.

A study by Zhou et al. (8) described exposure to formaldehyde vapor (10 mg/m3 for two weeks) that led to a decrease in the epididymis sperm count and motility in rats, this study also showed that the activity of enzymatic antioxidants decreased significantly in the testes of rats exposed to formaldehyde inhalation compared to the control group. One possibility for the reduction in sperm motility is that formaldehyde may cross the blood barrier thus inducing oxidative stress by increasing reactive oxygen species or decreasing antioxidant activity within the luminal surfaces. In a study by Kose et al. (26) concerning the effect of formaldehyde on rats' reproductive systems, the experimental animals were exposed to formaldehyde vapor (10 ppm/1h) for 35 days and the detrimental effects of formaldehyde on sperm count, motility and normal morphology were observed.

The findings obtained from the long-term sperm analysis in our study are compatible with the results of the above studies. The present research showed that formaldehyde vapor decreased sperm progressive motility. According to Mazilli, et al. (27) non-progressive, immotile and abnormal sperm can produce anion superoxidase, which is an oxidative factor in itself and this can decrease sperm quality, including sperm motility. In the current study, animals sacrificed 24 hours after formaldehyde exposure showed slight histopathological changes in the testes tissues. In contrast, the results of a histological examination in the $\mathrm{F}$ and NF experimental groups (long-term analysis) revealed that seminiferous epithelial cell degeneration of some seminiferous tubules had occurred, increasing the inter-tubular spaces and reducing the means of the seminiferous tubular diameter (STD). Ozen et al., (7) revealed that sub-chronic exposure to formaldehyde (5-10 ppm) for 91 days caused significant reductions in tubular diameters $(P<0.001)$. The experimental study of Golalipour et al., (28) also showed that formaldehyde vapor exposure for 18 weeks on rats, can induce histological changes in seminiferous tubules due to a significant decrease in the STD mean.

Zhou et al., (8) described how exposure to formaldehyde vapor (10 mg/m3 for two weeks) led to the atrophication of seminiferous tubules, decreasing numbers of spermatogenesis cells and seminiferous epithelial cell disintegration. With regard to the findings of our study, formaldehyde vapor alone and simultaneous exposure at the concentration levels and duration previously mentioned, are able to cause histological changes in the seminiferous epithelium and decrease the mean of seminiferous tubular diameters (STD) in mice. The morphometric findings obtained from the present study are in line with the findings of Golalipour et al. (28). In a study by Kose et al., (26) about the effect of formaldehyde on rat reproductive systems, experimental animals were exposed to formaldehyde vapor (10 ppm/1h) for 35 days and the detrimental effects of formaldehyde on sperm count, motility and normal morphology were observed. They also reported a relationship between the reductions of the seminiferous tubular diameters and a decrease in the number of Leydig cells in rats. Furthermore, Henkel et al., (29) determined a direct correlation between sperm motility and a 
decrease in the number of Leydig cells.

According to a study by Tang et al.,(8) an intraperitoneal injection of formaldehyde with dosages of $0.2,2$ and 20 $(\mathrm{mg} / \mathrm{Kg}$ ) have a negative impact on sperm count, viability and sperm motility in rats. They reported that seminiferous tubules atrophy and degeneration of seminiferous tubules led to a reduction in sperm counts. The findings obtained from the long-term sperm analysis in our study are compatible with the results of the above studies. Furthermore, the results of the long- term analysis (35 days after the end of exposure) revealed that there was a significant difference between the experimental groups $F$ and NF, in terms of progressive motile sperm. Another explanation regarding the findings of our study (decrease in motility and sperm viability), may be that noise and formaldehyde vapor exposure has an effect on the hypothalamus-pituitary-testis (HPT) axis in mice, which leads to a decrease in the levels of sex androgen hormones. In addition, our study showed that a decrease in testosterone hormone levels occurred in all experimental groups compared to the control.

It was shown that chemical and physical stress could increase the level of glucocorticoid hormones such as cortisol $(30,31)$, which directly or indirectly inhibit secretion of sex hormones and gonadotropin releasing hormones (10-13). The findings of the researchers obtained from the experiments performed on different animal models have indicated that increasing cortisol caused a decrease in secretion pulses $\mathrm{GnRH}$ and $\mathrm{LH}$ in addition to decreases in testis endocrine function (32). On the other hand, formaldehyde and noise may, via two specific mechanisms, have an effect on spermatogenesis and sperm parameters; first by changing the composition and structure of seminiferous tubules and dysfunction in the spermatogenesis process, and second by influencing the hypothalamichypophyseal-gonadal axis. In this regard Sari et al. (10) revealed that chronic exposure to low concentrations of formaldehyde (82-1874 ppb) affected the hypothalamushypophyseal-adrenal (HPA) axis and increased the secretion of corticotrophin releasing hormones (CRH) consequently this increased adrenal corticosteroid. Moreover, in the study by Sorg et al, (31) it was confirmed that corticosterone levels increased in rats, due to the effects of frequent exposure to low concentrations of formaldehyde. Furthermore in agreement with our results, Swami et al. (12) reported changes in testis tissue and a decrease in serum testosterone in rats exposed to $100 \mathrm{~dB}$ noise. Fathollahi et al. (13) observed that testosterone hormones decreased in rats which were exposed to 90-130 dB noise. As a result of the close relationship between the sub-cortical structure of the central nervous system and the auditory system in mice, noise could have an influence on the hypothalamus-hypophyseal-adrenal system through activation of this axis by the corticotrophin releasing hormone (30).
With respect to the findings of our study, sub-acute exposure to high concentrations of formaldehyde vapor in the workplace, may lead to a decrease in testosterone and LH hormone levels and noise can potentiate these reduction levels. Our study also shows that simultaneous exposure to formaldehyde and noise can decrease the percentage of progressive motile sperms, along with the percentage of sperm viability. However, further investigation needs to be conducted in order to understand the mechanisms underlying the effects of gonadotropin secretion suppression on sperm velocity parameters and sperm swimming patterns.

\section{Acknowledgments}

This research was supported by financial aid from Tarbiat Modares University, Tehran, Iran. The authors would like to gratefully thank the Vice President of the Research Department of Tarbiat Modares University for their Contribution to this research.

\section{Authors' Contribution}

All authors have been worked equally.

\section{Financial Disclosure}

None declared.

\section{Funding/Support}

None declared.

\section{References}

1. Danzon MA, Van Leeuwen R, Krzyzanowski M. Air quality guidelines for Europe: World Health Organization, Regional Office for Europe. WHO. 2002;1(1):87-95

2. Tang X, Bai Y, Duong A, Smith MT, Li L, Zhang L. Formaldehyde in China: production, consumption, exposure levels, and health effects. Environ Int. 2009;35(8):1210-24

3. Baker EL, Melius JM, Millar JD. Surveillance of occupational illness and injury in the United States: current perspectives and future directions. J Public Health Policy. 1988;9(2):198-221.

4. Lercher P. Environmental noise and health: An integrated research perspective. Env Int.1996;22(1):117-29.

5. Arican RY, Sahin Z, Ustunel I, Sarikcioglu L, Ozdem S, Oguz $\mathrm{N}$. Effects of formaldehyde inhalation on the junctional proteins of nasal respiratory mucosa of rats. Exp Toxicol Pathol. 2009;61(4):297-305.

6. Chowdhury AR, Gautam AK, Patel KG, Trivedi HS. Steroidogenic inhibition in testicular tissue of formaldehyde exposed rats. In dian J Physiol Pharmacol.1992;36(3):162-8.

7. Tang M, Xie Y, Yi Y, Wang W. [Effects of formaldehyde on germ cells of male mice].J Hyg Res. 2003;32(6):544.

8. Zhou DX, Qiu SD, Zhang J, Tian H, Wang HX. The protective effect of vitamin $\mathrm{E}$ against oxidative damage caused by formaldehyde in the testes of adult rats. Asian J Androl. 2006;8(5):584-8.

9. Zhou D, Qiu S, Zhang J, Wang HX. Effect of Formaldehyde on Spermatogenesis and Testicular Morphology in Adult Rats.J US-China Med Sci. 2006;3(3):58-60.

10. Sari DK, Kuwahara S, Tsukamoto Y, Hori H, Kunugita N, Arashidani K, et al. Effect of prolonged exposure to low concentrations of formaldehyde on the corticotropin releasing hormone neurons in the hypothalamus and adrenocorticotropic hormone cells in 
the pituitary gland in female mice. Brain Res. 2004;1013(1):107-16.

11. Smith A, Miles C. Sex differences in the effects of noise and nightwork on performance efficiency. Work Stress. 1987;1(4):333-9.

12. Nordin NM. An audit of singleton breech deliveries in a hospital with a high rate of vaginal delivery. Malays J Med Sci.2007;14(1):28-37.

13. Fathollahi A, Jasemi M, Saki G. C52 Effect of noise stress on fertility of male rats and the protective effect of vitamin $C$ and vitamin E on its potential harmful effect. Eur Uro Supp. 2011;10(9):625-6.

14. Huan P, Fan W, Jin F. The investigation of combined effect of formaldehyde and noise on blood pressure. Occup Health and Emerg Rescue. 2001;19(1):6-7.

15. Chang JC, Steinhagen WH, Barrow C. Effect of single or repeated formaldehyde exposure on minute volume of B6C3F1 mice and F-344 rats. Toxicol Appl Pharmacol.1981;61(3):451-9.

16. Akbar-Khanzadeh F, Park CK. Field precision of formaldehyde sampling and analysis using NIOSH method 3500. Am Ind Hyg Assoc J.1997;58(9):657-60.

17. Arab MR, Heidari MH, Mashhadi R, Mirzaei R, Jahantigh M. Histological Study of the Toxic Effects of Solder Fumes on Spermatogenesis in Rats. Cell. 2011;13(1):5-10.

18. Cobo P, Murillo-Cuesta S, Cediel R, Moreno A, Lorenzo-García P, Varela-Nieto I. Design of a reverberant chamber for noise exposure experiments with small animals. App Acous. 2009;70(8):1034-40.

19. Motallebi Kashani M, Mortazavi SB, Khavanin A, Allameh A, Mirzaee R, Akbari M. Protective Effects of $\alpha$-Tocopherol on ABR Threshold Shift in Rabbits Exposed to Noise and Carbon Monoxide. Iran J Pharma Res. 2011;10(2):339-46.

20. Krause W. Computer-assisted semen analysis systems: comparison with routine evaluation and prognostic value in male fertility and assisted reproduction. Human Repro. 1995;10(suppl 1):60.

21. Organization W. WHO laboratory manual for the examination and processing of human semen. World Health Organization; 2010; Available from: http://whqlibdoc.who.int/publications/2010/9789241547789_eng.pdf.

22. Anjamrooz SH, Movahedin M, Mowla SI, Bairanvand SP. Assess- ment of morphological and functional changes in the mouse testis and epididymal sperms following busulfan treatment. Iran Biomed J. 2007;11(1):15-22.

23. Solati J, Hajikhani R, Zaeim RT. Effects of cypermethrin on sexual behaviour and plasma concentrations of pituitary-gonadal hormones. Int J Fertility Sterility. 2010;4(1):23-8.

24. Leblond CP, Clermont Y. Definition of the stages of the cycle of the seminiferous epithelium in the rat. Ann $N$ Y Acad Sci. 1952;55(4):548-73.

25. Oliveira H, Spano M, Santos C, Pereira Mde L. Adverse effects of cadmium exposure on mouse sperm. Reprod Toxicol. 2009;28(4):550-5.

26. Kose E, Sarsilmaz M, Tas U, Kavakli A, Turk G, Ozlem Dabak D, et al. Rose oil inhalation protects against formaldehyde-induced testicular damage in rats. Andrologia. 2012;44 (Suppl 1):342-8.

27. Mazzilli F, Rossi T, Marchesini M, Ronconi C, Dondero F. Superoxide anion in human semen related to seminal parameters and clinical aspects. Fertil Steril. 1994;62(4):862-8.

28. Golalipour MJ, Azarhoush R, Ghafari S, Gharravi AM, Fazeli SA, Davarian A. Formaldehyde exposure induces histopathological and morphometric changes in the rat testis. Folia Morphol (Warsz). 2007;66(3):167-71.

29. Henkel R, Maass G, Schuppe HC, Jung A, Schubert J, Schill WB. Molecular aspects of declining sperm motility in older men. Fertil Steril. 2005;84(5):1430-7.

30. Knol BW. Stress and the endocrine hypothalamus-pituitary-testis system: a review. Vet Q.1991;13(2):104-14.

31. Sorg BA, Bailie TM, Tschirgi ML, Li N, Wu WR. Exposure to repeated low-level formaldehyde in rats increases basal corticosterone levels and enhances the corticosterone response to subsequent formaldehyde. Brain Res. 2001;898(2):314-20.

32. Debus N, Breen KM, Barrell GK, Billings HJ, Brown M, Young EA, et al. Does cortisol mediate endotoxin-induced inhibition of pulsatile luteinizing hormone and gonadotropin-releasing hormone secretion? Endocrinology. 2002;143(10):3748-58. 